\title{
The double path of light in ancient times: Lessons for Science Educational Practice
}

\author{
Joaquín Vidal-López \\ School of Advanced Education, Research and Accreditation (SAERA), Spain \\ Emotion, Cognition and Action Research Group in the Catholic University of Valencia, Spain \\ info@saera.eu
}

\begin{abstract}
The light has been part of myths, scientific explanations, and theories of mind from the origin of mankind. In this concern to explain cosmogony detached from the gods, the ancient Greeks began to seek the foundation of primordial matter from which it derives everything that exists. In this work are explained some approaches to the study of light from the first religious traditions, some Greek authors (Plato, Democritus, and Euclid), one medieval author (Grosseteste), and the last developments in the study of light carried out in the last century. This work is shown how a physical concept as light can be understood from a wide variety of perspectives along centuries and cultures. The actual knowledge of light, based on Einstein's Relativity Theory and Quantum Physics, is also explained. At the end of this work is exposed to one reflection about how myths and rational explanations are always combined for explaining natural events, and how both paths are valuable because they have different characteristics and purposes.Both mythical and rational perspectives coexist today in our society. They have different purposes, advantages and limitations. This approach is very useful for Primary and Secondary Science students, because it helps them to know the development of a key concept of physics (light) that is still revised today.
\end{abstract}

Keywords:

Light; Philosophy of Science; vision

This is an open access article under the CC-BY-NC license.

\section{INTRODUCTION}

The objects and events that are part of our daily reality can be explained from different perspectives or paradigms (Kuhn, 1962). Each of these explanations reflects the historical period in which they were formulated. They also offer us relationships with other concepts and aspects of reality that are ignored from the rest of the paradigms.

Modern science tends to see the transition from myth to logos as a crucial step in the history of mankind, from the irrational or pre-scientific explanation of natural phenomena to another more objective, stable in time and accurate way to see the world. However, both perspectives are valuable today, because both show us some aspects of our reality.

The purpose of this work is to explain briefly how this change occurred with the physical magnitude of light. How were the first explanations of light in ancient times, and how they were developed along the centuries until arriving at the present. This example could help to teachers of Primary and Secondary Schools to explain to their students how 
scientific concepts do not have a single explanation and how these are not stable over time, but evolves, even faster than myths. In addition, as we approach the current era, many of these explanations become more difficult to understand based on our daily sensitive experience, and we get closer to explanations that have many similarities to the myths of ancient times.

\section{THEORETICAL PERSPECTIVES}

\section{The light in ancient times}

The light is necessary for our survival as air or water. Without light in a very short time, the plants would perish and life on Earth would be impossible. It is not surprising, therefore, that the light concept has been part of myths, scientific explanations, and theories of mind from the origin of mankind.

Early civilizations conferred a divine character to light. For the ancient Egyptians, the most powerful symbol was the eye of Re, the sun god. The Litany of Re, funerary text that appears on the walls of the tombs of many Egyptian pharaohs of the New Empire (between 1550 and $1070 \mathrm{BC}$ ) indicated that Re was the "supreme power, lord of light, which reveals hidden things, the spirit that speaks to the gods in their fields" (Piankoff, 1964). It was also a creative being because "... you have grown, Re, those who are and those who are not, the dead, the gods, the intellects; its shape is the creator of bodies" (Piankoff, 1964). Therefore, the god Re gave not only life and light, but also "enlightened" intelligence.
The Persian people also gave a special power to light, and it was one of the forces worshiped by them, along with fire, air and earth (Gallardo, 2007). Zoroastrianism was one of the first monotheistic religions that emerged in Persia. In this tradition, Ahura Mazda was the lord of creation, truth, goodness, fire, and light; which in turn he was confronted with his twin brother Angra Mainyu, who chose consciously evil, created the disease, made death appear, and corrupted the pure fire, giving color to it and making that it contained smoke (i.e., impurities, pollution). This conception of light is described in some of the most outstanding works of Zoroastrianism, as the Ahunavaiti Gatha, in which it says: "At first [Ahura Mazda] thought so: the blessed realms be filled with light. He is the one who, by his wisdom, set it right. The best thought possesses those who extol you. Oh Mazda, through the Spirit, Oh Ahura, which is always the same" (Mills, 1887). The light is again vital for the creation of the world and is associated with terms like the good, the right thinking and the eternal spirit. Hom Yast is the Zoroastrian creed, and it includes in this recitation: "I attribute all good to Ahura Mazda [...] who is the light, that areas of happiness are filled with light" (Mills, 1887).

In the Rig Veda, known as the oldest text of India, light is associated with Indra (lord of heaven and king of other gods). "He is the one who, by his sovereign power, created all the worlds, who has brought light to heaven and earth, who are dispelling the darkness, repelled their baleful influence" (Langlois, 1848). Indra is also the "strong 
god that never yields [...] god of deep, vast, unattainable wisdom; who accelerates the good, the demolisher, the solid, the immeasurable; Indra whose rites bring joy, has made the light of dawn" (Griffith, 1889). When we fall into error, we also found a direct relation to light and darkness; therefore, when we sin against various gods, in the Rig Veda, the reciters implore them: "forgive us, for we have sinned against you. Can we get a wide light free of hazard? Oh, Indra, do not let us that we are trapped in the dark" (Griffith, 1889).

Also, at the beginning of Genesis: "God created the heavens and the earth. The earth was chaos and darkness over the abyss, and a wind of God hovered over the waters. God said, "Let there be light," and there was light. God saw that it was good, and God divided the light from the darkness; and God called the light "day" and the darkness "night»" (Desclée Brouwer, 1975). God also made "the two great lights; the big one for the domain of the day, and the lesser light to rule the night and the stars; and God set them in the celestial firmament to light upon the earth, and to rule the day and night, and to divide the light from the darkness, and God saw that it was good " (Desclée Brouwer, 1975).

In almost all accounts of the creation of the world, the light brought life, security, and justice. The darkness was associated with evil, confusion, error, and danger. This vision of light was well-grounded in everyday human experience. However, with the advent of philosophy in ancient Greece, something changed. Now light became to be understood as a natural phenomenon, detached from a mythical or religious explanation. Was the light something other than good, justice, or life? Was it something emanating from us towards the objects to enable us its understanding?

\section{Towards a rational explanation of the world}

In its concern to explain cosmogony detached from the gods, the ancient Greeks began to seek the foundation of primordial matter from which it derives all that exists (Gallardo, 2007).

Plato (427-347 BC) explains in the Allegory of the Sun that it appears in the book VI of the Republic that this star (which was a god for the ancient Greeks) allows not only to create life, growth, and nutrition. But "eyes, when they turn on the objects whose colors are no longer illuminated by daylight, but by the glow of the moon, look faintly as if they were not clearly in sight," while "when the sun shines on them, they see clearly, and it seems as if these same eyes had clarity" (Plato 1988). Plato does not attempt to formulate a theory about the nature of light with this allegory, but compare two ideas. In the same way that the sun allows, through the eyes, knowing sensible objects, so the Idea of Good allows, through intelligence, knowing the other Ideas. "What brings the truth to the knowable things and gives the one who knows the power of knowing [...] is the Idea of Good" (Plato 1988). But in terms of vision, it is important that Plato makes a distinction between three elements that must be taken so that we can see: the view, the sun, and light. The view identifies with "our eye," the sun was considered a god and a celestial body. But what was the nature of light to Plato? Was it something that 
came from the sun, even if it was not the sun? Or was it something that came from the objects or from us? In the Republic, he tells us that "the color is present in the objects" (Plato 1988). But the color is not light because without light, the object will not be seen, and the sun is the author of "that by which light causes the eye views and beautiful things to be seen" and the power of vision is "something like a fluid that is dispensed by the sun" (Plato 1988). Thus, light and sight are "related to the sun," but it would be wrong to believe that light is the sun. As with the brightness of the moon, we are also able to see objects, though less clearly, somehow Plato seems to mean that the light is in the middle, it needs the sun to increase its clarity and thus facilitate the sharpness in vision that we find necessary.

For the first time, Plato hypothesizes that light and the Idea of God are separate things. Light acts with eyes and objects to allow us sensory experience. Our intellect uses the Idea of God to enable our knowledge of science and truth. Contrary to what was happening with the mythical or religious traditions, in which the ideas of God, creation, light, and good were closely related, begins here a separation between these concepts that will become increasingly evident. In his Allegory of the Line, knowledge of the sensible world is only able to generate opinion (conjecture and beliefs), while knowledge of the intelligible world uses ideas (to generate intellectual intuition) and mathematical entities (to generate discursive thinking).
At the same time, as Plato and his teacher Socrates separated the light from the Idea of God in Athens, it was developed in Abdera, the atomistic school, in which Democritus (circa 460 -370 BC) was one of its greatest exponents. This philosopher proposed a theory of vision that:

1. The objects give off an image or eidola flowing and entering through the eyes.

2. The air through which it moves, transmitted with light particles from the sun, is condensed, i.e., prepares for printing the image.

3. As the image press condensed air, emanations from the eyes (visual rays) provide simultaneous understanding. The action of both emanations molds the air and ends up causing an impression.

4. As the image and printing in the air approaches the eye, the air density increases by the higher density of the emanations of visual rays. The compression process increase until the image and the printing are small enough to be introduced by the pupil.

5. When the printing and the image enter through the observer's soft and wet eye, it allows the image to move through body passages (Rudolph, 2011).

Plato also explains this idea of the rays coming out of his eyes to meet daylight in the Timaeus: "eyes [are] light-bearers; because the eyes enclose an inner fire that does not burn, and which is properly light; and from the contact between the inside and outside lights comes the sense of sight". 
Therefore "when daylight meets the current of visual fire, intimately joining the similar with the similar, it is formed in the direction of the eyes a single body, where the outer and inner lights are confusing. This luminous body [...] makes us experience the feeling we call sight (Plato, 1872).

A few centuries later, Euclid took into consideration this idea of Plato, and in 280 BC proposed that it could be considered that light rays originated in the eyes and projected on the object we are seeing. The speed of this projection would be very quick because we can close our eyes and not see, but when we open them, we see immediately objects that are far away (Bova, 2001). Euclid did not talk about the physical nature of these visual rays because he was only interested in applying geometry to study the perspective of the objects seen at a distance (Zubairy, 2016). However, we can see how, in this author, visual rays appear totally detached from the ideas of good, creation, or justice. They seem to have a separate existence of other metaphysical concepts and depend only on the perspective that is formed between the observer and the observed object. This relationship is governed by the geometry.

Aristotle (384-322 BC), Euclid (325-265 BC) and Ptolemy (circa 100-170 AD) continued proposing theories of light and vision increasingly divorced from the idea of good, justice, life and growth. The last great thinker who tried to combine both perspectives was Grosseteste (1175-1253). This author still considered light as a central element in the creation of the world. Therefore, the light would be for him, "which creates, modifies and expands the universe." It would not be the creator only of the physical world, but there must also be a divine light which is embodied in the spiritual creations of God. In short, we have life, and we have light because we have been granted by a Supreme Being.

With Grosseteste end the attempts to combine light as a physical element and as a means of the divine inspiration of life, intelligence, or good. Soon begins the Modern Age in Europe, where the mathematization of light conducted by Newton (1643-1727) will enter this phenomenon in the exclusive world of physics.

\section{FINDINGS AND DISCUSSION}

The myth and logos, two-way access to knowledge of the world

As we have seen, humans of antiquity tried to explain reality with observation means at their disposal. From these observations, they performed theories trying to give meaning to the world and make their environment more predictable.

The use of myths was one of those strategies. In general, myths have many advantages:

- They are stories that offer a synthetic explanation (in which various aspects of reality are addressed in the same explanation).

- They often offer deep explanations and full of meaning for the culture in which these myths are given because they explain aspects of the origin, existence, 
development, and even the future of civilization.

- Little changes are transmitted over many generations, allowing a sense of stability in the culture, beyond particular individuals, security and even predictability in the events that happen in the world.

- They do not intend to be a true reflection of reality but access the deeper meaning of world events that often do not show obviously to all.

On the contrary, the logical explanation of reality focuses on making other approaches:

- It pretends to explain things as they are, regardless of tradition, or security needs or cohesion that may have a particular civilization.

- It is changing. Often each author, each generation, or even each published work offers different explanations, even contradictory between them.

- It not intended to provide a deep explanation of the facts, anchored more on intuition, but based on logic and direct observation and (evident) facts.

- $\quad$ Striving for objectivity and frequent changes in theories are accepted naturally.

- $\quad$ The classic texts are more a burden than a source of inspiration for the understanding of reality (as with the mythical explanations).

\section{Applications in education}

Both rational (logos) as the mythical explanations are very present in today's society. Modern society offers many opportunities to access mythological explanations (cultural and religious traditions, literature, movies, video games, virtual reality environments, etc.).

In modern societies, there is a strong presence of the hypothetical-deductive method. Therefore, scientific explanations of reality enjoy great prestige.

However, as we advance in knowledge, we realize the inadequacy of the rational scientific method to explain many phenomena. We know that the first logical attempts to explain the world by the Greeks had their mistakes. But what happens to our current knowledge about light? Do not also have limitations and paradoxes? Here are some of them:

- Is light a wave or a particle? According to the experiment we conduct, the light will behave as a particulate object moving in a straight line (photon) or a wave devoid of matter that moves sinusoidally (as a wave). Is it both at once? Or is it not one of them? We do not still fully understand this duality.

- According to current science, light always travels at the same speed. If an object that emits light moves very fast is the time which deforms so that the speed of light remains constant (Einstein's Theory of Relativity). However, the light waves are compressed or expanded as the object is approaching or moving away from us (Doppler Effect). 
- When light strikes an extremely small object, it causes the object to change its speed or position. This causes that we will never be able to simultaneously determine the velocity and position of a subatomic particle (Heisenberg Uncertainty Principle) accurately.

- Waves can interfere with each other. For example, if we put two small slits generating light diffraction, waves that emerge from one slit interfere with the waves coming from the other, causing an interference pattern. But what happens when we only send one photon every time? In this case, each photon interferes with the rest that has been emitted at different times. We see how light and time have complex interactions difficult to explain today.

We see, therefore, how rational explanations that the Greeks tried to disentangle from the myths are becoming darker, counterintuitive, designed to clarify a deep structure of reality, and they are more beyond the observable evidence.

\section{CONCLUSION}

In some way, myths are now more present than ever and will remain for many centuries, because they are a necessary and unique way to access some aspects of our understanding of the world that are forbidden by other access routes to reality.

It is advisable to include in the curricula of science subjects, sessions in which the historical evolution of some scientific concepts can be seen. This will help students to better understand how we have reached the current scientific knowledge and will allow them to understand, in a better way, the effort made by ancient human beings to understand and explain the world around them.

\section{REFERENCES}

Bova, B. (2001). Historia de la Luz. Madrid: Espasa.

Desclée de Brouwer. (1975). Biblia de Jerusalén. Bilbao: Desclée de Brouwer.

Gallardo, S. (2007). Historia de la Luz. Buenos Aires: Capital Intelectual.

Griffith, R. (1889). The Rig Veda. Benarés: E.J. Lazarus \& Co.

Kuhn, T. (1962). The Structure of Scientific Revolutions. Chicago: University of Chicago Press.

Langlois, M. (1848). Rig Véda, ou Livre des Hymnes. Paris: Librairie de Firmin Didot Frères.

Mills, L. (1887). The Zend-Avesta. Parte III. The Yasna, Visparad, Afrinagan, Gahs, and Miscellanious Fragments. Oxford: Clarendon Press.

Piankoff, A. (1964). The Litany of Re. Nueva York: Pantheon Books.

Platón. (1988). República. Madrid: Editorial Gredos. Platón. (1872). Timeo. Madrid: Edición de Patricio Azcárate.

Rudolph, K. (2011). Democritus' Perspectival Theory of Vision. The Journal of Hellenic Studies , 6783. 
Zubairy, M. (2016). A Brief History of Light. In M. E.-

Berlín:

Springer.

G. Al-Amri, Optics in Our Time (pp. 3-24). 